\title{
Development of methods of operational and production management of construction of nuclear facilities
}

\author{
Sergey Sborshikov, Roman Vvedenskiy, Irina Markova* \\ Moscow State University of Civil Engineering, Yaroslavskoe shosse, 26, Moscow, 129337, Russia
}

\begin{abstract}
The adoption of appropriate tactical decisions is central to the organization of operational and production controlling in the construction industry. The article discusses the issues of using simulation modelling when optimizing the schedule for performing a complex of construction and installation works performed in the process of operational and production control.
\end{abstract}

\section{Introduction}

The construction of capital construction facilities, including facilities for the use of atomic energy, is characterized by the presence of a large number of disturbing influences of various nature (technical, economic, social), which can unbalance the system of construction production and, as a consequence of this, the manifestation of negative consequences - disruption of construction time, an increase in costs, decrease in the quality of construction products.

In this regard, an effective system is needed that is able to adequately and timely respond to the disturbing factors of the external and internal environment, as well as bringing it into a certain framework of the development trajectory of an investment and construction project. At the same time, such a system should take into account modern management practices and advanced approaches to the organization of construction, dictated by scientific and technological progress.

Organizational and technological convergence, an engineering scheme for construction management, and the concept of the life cycle of buildings (structures) can be considered such phenomena. Their integration in a single structure allows us to propose the formation of a production and engineering centre at the construction site (Fig.1).

*Corresponding author: markova@mgsu.ru 


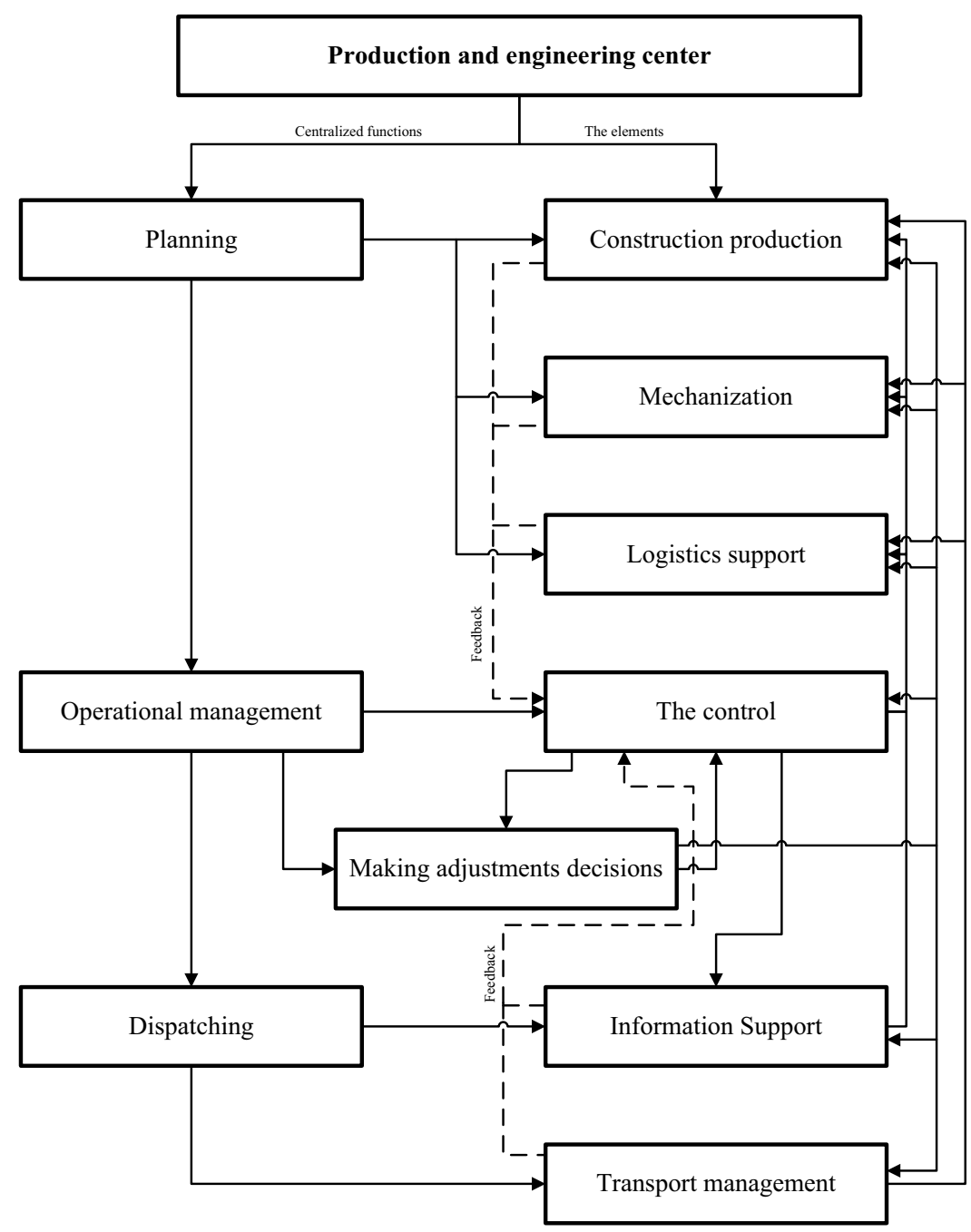

Fig. 1. Basic functions implementation diagram production and engineering center

\section{Methods}

The postulate that the creation of a unified and effective operational management system that meets the modern challenges of construction practice should include the following subsystems as the starting point of the study (Fig. 2):

- operational and production planning;

- operational dispatch control;

- operational production controlling.

The main tasks of the latter are: monitoring on an ongoing basis the execution of operational plans (tasks) and providing feedback to the operational-production planning subsystem in order to adjust (clarify) operational plans, i.e., including making operational decisions (technical and managerial). 


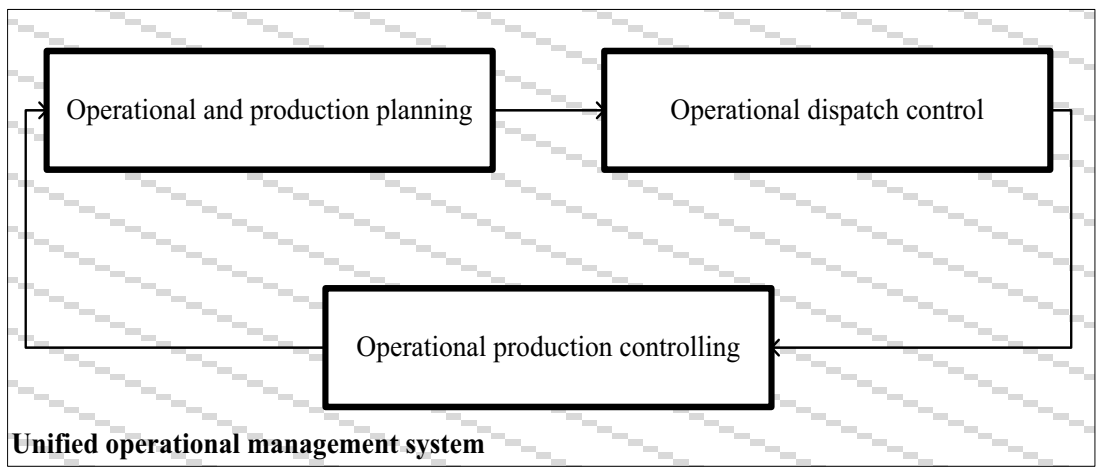

Fig. 2. Scheme of a unified system of operational management in construction

The main tasks of the latter are: monitoring on an ongoing basis the execution of operational plans (tasks) and providing feedback to the operational-production planning subsystem in order to adjust (clarify) operational plans, i.e., including making operational decisions (technical and managerial). [1-4]

Thus, it is possible to note and functionally distinguish two components of operational and production controlling:

- operational control;

- making operational decisions.

It also seems necessary to point out a certain hierarchy of such systems and the connection between the studied subsystem and the strategic controlling subsystem, which has similar components. In this regard, taking into account the indicated similarity of strategic and operational-production controlling, as well as the specifics of the construction of technically complex and unique objects, we can propose their integration into a single organizational structure - integral control.

\section{Results and discussion}

The organization of operational and production planning and management of the same name, both in the Russian Federation and abroad, is based on the theory and practice of scheduling, recently supplemented by the project management paradigm. The current structure of capital construction projects management of SAEC Rosatom is shown in Fig. 3.

In accordance with this paradigm, a construction project management system is a set of resource management processes and tools designed to achieve the goals of a construction project.

Project management systems in construction can be classified as:

1. a separate project, including using BIM;

2. part of the project implemented by the contractor as an independent project;

3. a complex (portfolio) of projects of integrated (horizontally or vertically) structures.

The organization of project management, depending on the nature of the work, can be formed on the basis of:

- economic method - implementation of construction by the developer's own resources;

- contracting method - implementation of construction by the forces of thirdparty contracting companies.

Distinguish between: general contracting and engineering schemes. [5-7] 
All project management activities are divided into processes, works or their complexes (enlarged groups of works), which are decomposed into activities and control events (stages).

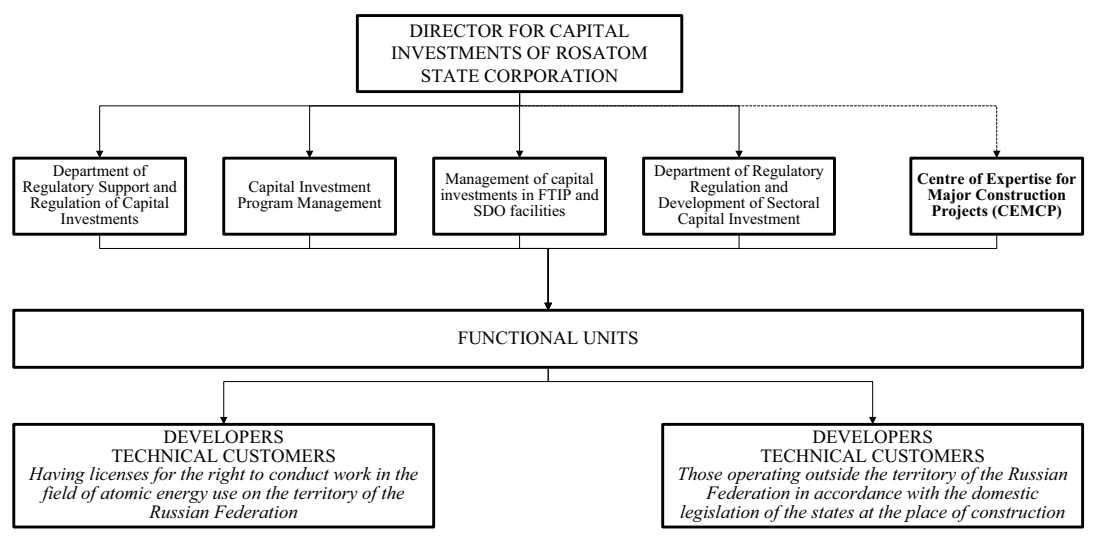

Fig. 3. The current structure of capital construction project management SAEC Rosatom

The supporting processes of project management are:

- stimulating the motivation of participants in investment and construction activities;

- ensuring the required level of competence of participants in investment and construction activities and its systematic increase;

- technical support for project management.

The specified grouping of processes is subjective and can be of a different form or can be expanded.

The basis of project management is scheduling, which involves the establishment of:

- nomenclature of processes, works, activities;

- list of control events;

- technological sequence;

- responsible executors;

- the duration of the implementation of processes, works, activities and, if linked to a calendar, their timing;

- timing of achievement of milestones.

Control events are divided into tactical level control events - from the passport of the investment project, and operational level - having an intermediate or local purpose.

Documenting the execution of work or the progress of construction within the framework of project management at a certain period of the timeline has the form of a report, which includes:

- data on the actual achievement of milestones or the reasons for not achieving them,

- forecast of achievement of milestones of the next period or violation of terms,

- information about the risks and how to damp them,

- information on key results achieved over the past period, problems requiring management intervention.

Also, the report may contain information about the state of the budget of the investment project. [8-10]

In this regard, corporate management documents should provide the ability to measure parameters and identify specific features of construction projects, for this a typology of 
construction projects is formed. Objects-representatives of this typology have a nomenclature and sequence of processes (work) characteristic only for their group and are the basis of the schedule for the implementation of a construction project, with the help of which, as well as standard forms (traffic schedules, deliveries, etc.) and software systems are formed organizational and technological model of the project

On the basis of the organizational and technological model of the project, a standard system of measures for monitoring the implementation of a construction project is being developed. The specific features of specific projects are taken into account by linking the organizational and technological model of the project to the construction conditions and the corresponding adjustment of the nomenclature and sequence of works, distribution and assignment of processes to individual participants.

In this case, the adjusted organizational and technological model must correspond to the schedule adopted in the construction organization project, be detailed in the work production project. In the future, the adopted system of control measures is also adjusted, which is the basis for generating reports on the construction project.

At the final stage, the organizational structures of the participants, implementing the construction project, are formed or adjusted.

Organizational support of project management is achieved through the creation of specialized structural units and services within the framework of an economic entity implementing a construction project

It is necessary to point out the rather rapid development of new forms of organization of construction, especially those related to engineering, which contributes to the isolation of such a participant in investment and construction activities as a construction organizer, taking on the functions of a coordinator of the work of all participants in the construction of an object, and to whom the functions implemented at the construction site by the manager are delegated project, customer, general contractor. Many experts have repeatedly pointed out that such aggregation helps to reduce risks, primarily at the construction stage, and it is on the basis of engineering principles that the above functions can be integrated and effectively performed.

The separation of the construction organizer and, consequently, the change in the distribution of functions between the project participants transforms the spheres of competence of the subjects of investment and construction activities and leads to the reengineering of both management processes and the organizational structure.

The traditional (general contracting) scheme for organizing construction management is stagnating under the influence of objective factors, so some construction companies, explicitly or implicitly, completely or partially switch to the engineering scheme.

Separation of the construction organizer as a separate independent entity at the level of a construction site is an important element in the formation of an engineering management scheme. Both engineering companies and individual divisions of companies that manage investment and construction projects or operate an atomic energy facility with similar competencies can act as organizers of construction.

In accordance with industry terminology, an engineering company is a legal entity that provides a range of engineering services, including the preparation and development of design and working documentation, carrying out the construction of nuclear power facilities, including the purchase of equipment and performing the functions of a general contractor and general designer. The operating organization of the facility bears "full responsibility for the safety of a nuclear installation" at all stages of the life cycle, which means placement, design (including surveys), design, production, construction or construction (including installation, commissioning, commissioning), operation, decommissioning (closing).

Considering the above, during the construction of an atomic energy use facility, the 
generally accepted engineering scheme has changed. The developer himself performs the functions of a technical customer, and concludes a general contract for the construction of a nuclear power plant with engineering companies. The engineering company is responsible for carrying out work on the development of working documentation, on organizing construction and installation work, on contracting and supplying equipment to nuclear power plants.

The adoption of the appropriate tactical decisions by the construction organizer is the central point in the organization of operational and production controlling. In this regard, one of the promising ways can be the use of optimization methods in combination with simulation models. [11-16]

Thus, the problem of forming solutions is formulated as follows: for given values of uncontrollable factors, it is necessary to find such values of controls from the range of their permissible values, at which a maximum (minimum) is achieved according to the optimality criterion.

In this regard, to solve the problem of forming a calendar schedule that has a given level of organizational and technological reliability, it is possible to propose a method for improving the plan according to a given criterion, which depends on the nature of the supply of resources to the object.

The procedure for forming a calendar schedule for performing a complex of construction and installation works with a given level of organizational and technological reliability can be described by the following sequence of steps:

1. Some initial schedule is set.

2. The calendar schedule is tested for local changes in resources that are not outside the original limits.

3. For a given set of resources, the moments of their supply are determined.

4. The main constraint is checked, which is considered the requirement that the probability of completing a complex of works on time should be not less than the selected reliability level. If the main constraint is met, then the obtained values are taken as the calendar schedule. Otherwise, the value is sequentially halved until a value satisfying the main constraint is obtained.

5. We check the condition of the end of the account. If the adjacent two iterations differ little from each other, then the counting stops, otherwise we return to item 2.

\section{Conclusions}

The adoption of appropriate tactical decisions by the construction organizer is a key moment in the organization of operational and production controlling. The model can be used both independently to study and evaluate various options for the structure of the calendar schedule of construction and installation works, and as an integral part of the software for the subsystem of operational and production controlling the construction of nuclear facilities.

\section{Reference}

1. S.B. Sborshchikov Diss. Dr. Econ. sciences Logistics of regulatory influences in the investment and construction sector (theory, methodology, practice) (2012)

2. N.V. Lazareva Diss. Cand. Tech. sciences Cluster model of the organization of innovative activities at the corporate level in construction (2015)

3. G.N. Shinkareva, L. A. Maslova L Sc. Review 18 (2016) 
4. A.V. Ginzburg, G.N. Shinkareva Cyber-physical building systems: collection of articles. mat. Sem., held within the VI Inter. scientific. conf. Moscow MGSU (2018)

5. P.A. Zhuravlev Bulletin of the Irkutsk State Technical University, 9 (104), (2015)

6. A.V. Alexanin, Scientific Review, 6 (2017)

7. Ya. V. Zharov production in the energy sector Civil Ing. Jr. No 11 pp 83-85 (2013)

8. D.N. Silka, E.E. Ermolaev, E E Naukovedenie Int. Jr. 1 (20), (2014)

9. P.A. Zhuravlev, Bulletin of the Belgorod State Technological University,7 (2017)

10. P.A. Zhuravlev P A and E.M. Kochenkova, Industrial and civil construction J., 6 (2019)

11. V.D. Klyuev, P.A. Zhuravlev, A.V. Levchenko Scientific Review 1 (2014)

12. T.V. Khripkon Academic science - problems and achievements: mat. IX Int. sc.pract.conf. North Charleston, USA (2016)

13. D.M. Leibman, T.V. Khripko, E.E. Bondarenko Eurasia Science: collection of articles. Art. X Int. Sc.-pr. conf. Moscow Relevance RF (2017)

14. S.B. Sborshikov, L.A. Maslova, P.A. Zhuravlev, Ind.and civ. Constr.J., 7 (2018)

15. S.B. Sborshikov, L.A. Maslova, Vestnik MGSU, 14, 7 (2019)

16. S.B. Sborshikov, L.A. Maslova, Vestnik MGSU, 14, 10 (2019) 